\title{
FORMULATION OF ATOVAQUONE TABLET USING BIOSURFACTANT IN A TERNARY SOLID DISPERSION SYSTEM: IN VITRO AND IN VIVO EVALUATION
}

\author{
UDAYKUMAR B. BOLMAL ${ }^{\mathrm{a}}$, PRAMOD H. J. ${ }^{\mathrm{b}}$
}

aDepartment of Pharmaceutics, KLE Academy of Higher Education and Research, Belagavi, Karnataka, India, bDepartment of Pharmaceutical Biotechnology, KLE College of Pharmacy, Nehru Nagar, Belagavi 590010, Karnataka, India

Email: udaybolmal@yahoo.co.in

Received: 25 Aug 2018, Revised and Accepted: 09 Jan 2019

\section{ABSTRACT}

Objective: The goal of the present investigation was to improve the solubility and bioavailability of atovaquone tablet, using in-house biosynthesized biosurfactant in the ternary system of solid dispersion containing hydrophilic polymers with varying concentrations of biosurfactant. Atovaquone is an anti-malarial agent and belongs to biopharmaceutical classification system class IV.

Methods: The solid dispersion of binary and ternary mixture was prepared using hydroxyl propyl methyl cellulose (HPMC) and biosurfactant respectively by a solvent evaporation method. All the atovaquone tablet formulations were prepared by incorporation of physical mixture, binary and ternary solid dispersed products with excipients by direct compression method. Pre-compression and post-compression parameters of atovaquone tablets were evaluated. In vivo bioavailability study was performed using female albino rabbits.

Results: In vitro dissolution profile of binary and ternary system of solid dispersion products showed $8.65 \%$ and $34.64 \%$ respectively. Precompression and post-compression values of all atovaquone tablets formulations were within the specified limits. In vitro dissolution efficiency of F2 and F5 were 1.44 fold and 6.62 fold respectively, in accordance to the F1. In vivo study revealed that bioavailability of optimized formulation F5 was increased by 2.5 times and time to reach peak concentration was reduced to $1.4 \mathrm{~h}$, in accordance to pure atovaquone suspension.

Conclusion: Potential application of biosurfactant in the solid dosage form of atovaquone tablet was proved for enhanced dissolution rate and bioavailability of atovaquone for malaria treatment.

Keywords: Atovaquone, Solid dispersion, Physical mixture, Ternary system, Biosurfactant, Bioavailability

(C) 2019 The Authors. Published by Innovare Academic Sciences Pvt Ltd. This is an open access article under the CC BY license (http://creativecommons.org/licenses/by/4.0/) DOI: http://dx.doi.org/10.22159/ijap.2019v11i2.29329

\section{INTRODUCTION}

Atovaquone is unique naphthoquinone with a broad-spectrum antiprotozoal agent, belongs to the biopharmaceutical classification system (BCS) class IV and exhibits low and variable oral bioavailability (46\%) due to its poor aqueous solubility (less than $0.25 \mu \mathrm{g} / \mathrm{ml}$ ) [1] Enhancement of dissolution and thereby its bioavailability is a primary requisite of an oral drug delivery of atovaquone. Numerous technologies have been developed for enhanced solubility of poorly water-soluble drug such as micronization, salt-formation, solid dispersion, complexation etc. Solid dispersion using a water-soluble carrier system is the most commercially viable technology applicable in recent years. The ternary system of solid dispersion is the addition of surfactants in a binary system and also plays essential processes of modification for maximum solubility of the drug in the aqueous fluid [2].

Nonionic surfactants were used for enhancement of solubility of poorly water-soluble drug in the range of $5 \% \mathrm{w} / \mathrm{w}$ to $20 \% \mathrm{w} / \mathrm{w}$. Synthetic surfactants are non-biodegradable. In recent years novel biotechnological products are produced from various microorganisms through fermentation. Biosurfactants are produced from specific microorganisms with economic substrates such as waste fried oils, molasses etc, in a suitable media and environmental conditions. Major advantages of biosurfactants over the synthetic surfactants are, at low concentration maximum solubility of poorly soluble drugs, stable in all $\mathrm{pH}$ range, very less toxicity and biodegradability. This is due to its unique chemical composition with fatty acid, monosaccharide and amino acids $[3,4]$.

From the literature survey, it was revealed that the potential application of biosurfactant has not been explored as a solubility modulator and permeability catalyst for in-soluble and less permeable drugs. In this study, atovaquone drug was selected as model drug for its enhancement of solubility and permeability. The aim of our present study was to formulate atovaquone tablet of the physical mixture, binary and ternary solid dispersion system using water-soluble carrier hydroxyl propyl methyl cellulose (HPMC) with biosurfactant and compare its dissolution rate and bioavailability with poloaxmer 407 a nonionic surfactant.

\section{MATERIALS AND METHODS}

\section{Materials}

Gift sample of atovaquone was procured from Matrix Lab Ltd Hyderabad. Poloaxmer 407 from venous ethoxy ether Pvt Ltd, Goa. Hydroxypropyl methyl cellulose (HPMC) from Colorcon industry, Goa. Lactose, polyvinyl pyrrolidone (PVP), magnesium stearate and talc from Balji chemicals, Mumbai. All other chemicals were from SD fine chem India (AR grade).

\section{Methods}

\section{In-house biosynthesis of biosurfactant}

Biosurfactant was produced from the biotechnology processes using Flavobacterium Sp 2495(Chandigarh) in a modified mineral salt media. Molasses $5 \% \mathrm{w} / \mathrm{v}$, waste fried oil $5 \% \mathrm{w} / \mathrm{v}$ and $1 \% \mathrm{w} / \mathrm{v}$ peptone, $0.5 \% \mathrm{w} / \mathrm{v}$ ammonium chloride were used as carbon and nitrogen source respectively. Trace elements were ferric chloride and vitamin B6 Fermentation conditions were maintained at $\mathrm{pH}$ at 7.4 , temperature $32 \pm 1{ }^{\circ} \mathrm{C}$, aeration $40 \%$ and rpm 150 . Duration of fermentation was $72 \mathrm{~h}$ (sorotus lite fermentor). The fermented fluid was separated by solvent extraction using a methanol-water mixture (1:2). Purification was carried out using $5 \mathrm{~N}$ hydrochloric acid $(\mathrm{HCl})$ by the precipitation method. The product was dried at $40{ }^{\circ} \mathrm{C}$ for $3 \mathrm{~h}$ and passed through 60 mesh and stored in an airtight container at room temperature. An oral toxicity study was performed on albumin rats as per organization for economic co-operation and development (OECD) guidelines. It was found that $2000 \mathrm{mg}$ per $\mathrm{kg}$ body weight of albumin rats was safe without mortality and toxicity. The yield of biosurfactant was $2.5 \mathrm{~g}$ per liter [5].

\section{Preformulation studies}

\section{Compatibility studies}

Compatibility study of drug and excipients was carried out through fourier transmission infrared spectrophotometer (FTIR) (Shimadzu Japan) using potassium bromide $(\mathrm{KBr})$ probe technique, scanned from 4000-400 cm-1. Graphs were recorded and analyzed for comparatively for compatibility studies. 
The solid dispersion of atovaquone with HPMC and bio surfactant

Solvent evaporation technique was adopted for the preparation of the solid dispersion product. Atovaquone was dissolved in ethanol. Hydroxyl propyl methyl cellulose was dissolved in water in the ratio 1:2 (drug: polymer) using a magnetic stirrer. The drug solution was added to the aqueous hydroxyl propyl methyl cellulose solution with constant stirring. The ternary system was prepared by adding various concentrations of surfactants to the drug-polymer solution as shown in the table 1 . The mixture was evaporated on $8 \mathrm{~cm}$ diameter china dish for $48 \mathrm{~h}$ at room temperature. The solid mass obtained was dried at $40^{\circ} \mathrm{C}$ in the oven for $4 \mathrm{~h}$, pulverized, sieved through 60 mesh and stored in an airtight container until use [6, 7].

Table 1: Solid dispersion of atovaquone with hpmc and surfactants

\begin{tabular}{|c|c|c|c|c|c|c|c|c|c|}
\hline \multirow[t]{2}{*}{ Ingredients } & \multicolumn{6}{|c|}{ Formulation code } & \multirow[b]{2}{*}{ S5 } & \multirow[b]{2}{*}{ S6 } & \multirow[b]{2}{*}{ S7 } \\
\hline & Unit & So & S1 & S2 & S3 & S4 & & & \\
\hline Atovaquone & $\mathrm{mg}$ & 62.5 & 62.5 & 62.5 & 62.5 & 62.5 & 62.5 & 62.5 & 62.5 \\
\hline HPMC & $\mathrm{mg}$ & ---- & 125 & 125 & 125 & 125 & 125 & 125 & 125 \\
\hline Biosurfactant & $\mathrm{mg}$ & ---- & -- & 2 & 4 & 6 & - & - & --- \\
\hline Poloxamer407 & $\mathrm{mg}$ & ---- & -- & -- & - & - & 10 & 20 & 30 \\
\hline Ethanol & $\mathrm{ml}$ & ---- & 30 & 30 & 30 & 30 & 30 & 30 & 30 \\
\hline
\end{tabular}

\section{Preparation of atovaquone tablet using the solid dispersed product}

Compressed tablets containing physical mixture and solid dispersed product with and without surfactants were prepared separately by direct compression method. Diluent lactose, dry binder polyvinyl pyrrolidone, and lubricants talc, magnesium stearate were used as excipients. All ingredients were sieved through 40 mesh and blended with lubricants and compressed in 10 stations rotary machine (M/s Karnavati) at $6 \mathrm{~kg} / \mathrm{cm} 2$ hardness using $9 \mathrm{~mm}$ flat punches. All the formulation batches were shown in the table 2 .

Table 2: Formulation of atovaquone tablets

\begin{tabular}{|c|c|c|c|c|c|c|}
\hline \multirow[t]{2}{*}{ Ingredients (mg) } & \multicolumn{6}{|c|}{ Formulation code } \\
\hline & F1 & F2 & F3 & F4 & F5 & F6 \\
\hline Atovaquone & 62.5 & 62.5 & 62.5 & -- & -- & -- \\
\hline Solid dispersion system & --- & --- & --- & $\mathrm{S} 1$ & S3 & S7 \\
\hline Biosurfactant & -- & 4 & -- & -- & -- & -- \\
\hline Poloxamer407 & --- & -- & 30 & -- & -- & -- \\
\hline Lactose & 159.5 & 155.5 & 129.5 & 34.5 & 30.5 & 4.5 \\
\hline PVP & 5 & 5 & 5 & 5 & 5 & 5 \\
\hline Mg stearate & 1 & 1 & 1 & 1 & 1 & 1 \\
\hline Talc & 2 & 2 & 2 & 2 & 2 & 2 \\
\hline Total weight & 230 & 230 & 230 & 230 & 230 & 230 \\
\hline
\end{tabular}

S1, S3, S7. Solid dispersed products

\section{Evaluation of atovaquone solid dispersed products}

\section{In vitro dissolution}

All solid dispersion products and pure drug were subjected for dissolution profile using USP dissolution apparatus (Electro lab India TD 80) at $50 \mathrm{rpm}$ in $1.2 \mathrm{pH}$ buffer media for $1 \mathrm{~h}$. Sample equivalent to $62.5 \mathrm{mg}$ of atovaquone was placed in the tea bag and tied to the paddle. Aliquot samples were withdrawn from $900 \mathrm{ml}$ at specified intervals and analyzed using uv-vis spectrophotometer (UV 1900 Shimadzu Japan) at $\lambda \max 220 \mathrm{~nm}$ under sink condition [8].

\section{Evaluation of atovaquone tablets}

\section{Pre-compression}

All the formulation of atovaquone lubricated powder blends was subjected for micromeritics properties using conventional methods. Bulk density and tapped density was determined by using measuring cylinder method. Hausner's ratios, Carr's index, were determined using the bulk density and tapped density data. An angle of repose was determined by conventional funnel method [9].

\section{Post-compression}

All batches of atovaquone tablets were subjected to nonpharmacopieal and pharmacopieal tests. Tablet thickness, hardness, was determined using a vernier caliper and Monsanto hardness tester respectively. Friability, disintegration test was performed as per Indian pharmacopeia (IP 2014) [10].

\section{In vitro dissolution rate study}

The dissolution rate of atovaquone tablets prepared was studied in $900 \mathrm{ml}$ of acidic buffer of $\mathrm{pH} 1.2$ using USP dissolution apparatus type $\mathrm{I}$ at $50 \mathrm{rpm}$ and the $37 \pm 1{ }^{\circ} \mathrm{C}$ temperature was maintained throughout the study. Aliquot samples of dissolution media $(5 \mathrm{ml})$ were withdrawn through a filter $(0.45 \mu)$ syringe at different intervals of time up $60 \mathrm{~min}$. All the samples were suitably diluted and assayed at $\lambda \max 220 \mathrm{~nm}$ and sink condition was maintained $[11,12]$.

\section{Dissolution efficiency}

The concept of dissolution efficiency (DE) was proposed by Khan and Rodes in 1975 is defined by

$$
\mathrm{DEt} \%=\frac{\int_{0}^{\mathrm{t}} \mathrm{Y} \cdot \mathrm{dt}}{\mathrm{Q} 100 \mathrm{t}} \mathrm{X} 100
$$

Where $Y$ is the percentage of drug dissolved at any time t, Q100 is the 100 percentage of dissolved product, DE is the area under the dissolution curve between time points 0 and $t$ expressed as a percentage of the curve at maximum dissolution, Q100, over the same time period [13].

\section{In vivo bioavailability study}

Experiments were conducted in compliance with the committee for the purpose of control and supervision of experiments on animals (CPCSEA) and experimental protocol approval from institutional animal's ethics of our institution (Registered No221). Female albino rabbits (1.2 to $1.5 \mathrm{~kg}$ ) were used in the study. Animals were divided into two groups. Each group containing three rabbits was housed in polypropylene cages in a room with the controlled temperature of $25 \pm 3^{\circ} \mathrm{C}$ and relative humidity (RH) $60 \pm 5 \%$ in $12 \mathrm{~h}$ light $/ 12 \mathrm{~h}$ night cycle. The animals were fed with a standard pelleted diet and purified water ad libitum throughout the experiment. Group I and group II received atovaquone $(25 \mathrm{mg} / \mathrm{kg})$ oral suspension and optimized atovaquone tablet formulation (F5) respectively, through oral silicon tube after $12 \mathrm{~h}$ fasting. Blood samples were collected from the marginal vein of the ear of rabbits at an interval 
$0.5 \mathrm{~h}, 1 \mathrm{~h}, 3 \mathrm{~h}, 6 \mathrm{~h}, 12 \mathrm{~h}$ in a heparinized tube. Plasma samples were obtained by centrifuged at 5000Xg for $10 \mathrm{~min}$ and stored at $-20^{\circ} \mathrm{C}$ until analyzed. All the plasma samples were analyzed for drug content through high-performance liquid chromatography (HPLC SPD-M20A Shimadzu) with the following conditions. Chromatographic separation was developed for the quantitative serum level of atovaquone using column C18. Mobile phase consists of $0.1 \% \mathrm{v} / \mathrm{v}$ formic acid and methanol in the ratio of 20:80. The aqueous phase was eluted at a flow rate of 1 $\mathrm{ml} / \mathrm{min}$, volume injected was $20 \mu \mathrm{l}$ and retention time was 7 to $8 \mathrm{~min}$ with the $15 \mathrm{~min}$ run time. The effluent was monitored at UV $254 \mathrm{~nm}$. Standard calibration was constructed by spike method using a different concentration of drug in serum. All other chromatographic separation conditions were kept constant [14].

\section{Pharmacokinetic analysis of data}

The obtained data were expressed as mean \pm SEM. Student t-test and ANOVA were used to analyze and compare the results $p<0.05$ was considered significant in all the tests. Systat 13 software was used in the study.

Maximum peak plasma concentration (Cmax) and time to reach maximum plasma concentration ( $\mathrm{t}$ max) were obtained from the plasma concentration $\mathrm{v} / \mathrm{s}$ time graph, area under the curve (AUC) calculated from the trapezoidal rule [15].

\section{RESULTS AND DISCUSSION}

\section{Drug and excipients compatibility study}

The FTIR graph interpretation of atovaquone and excipients showed the characteristics peaks of atovaquone at $3375 \mathrm{~cm}-1(\mathrm{C}-\mathrm{O}$ stretch),1658 cm-1(aromatic $\quad \mathrm{C}=0 \quad$ stretch),729.09 $\mathrm{cm}-1(\mathrm{C}-\mathrm{Cl}$ stretch),2924(aromatic C-H stretch) were retained. No significant differences were observed, indicative of compatibility with drug and excipients. (fig. 1)

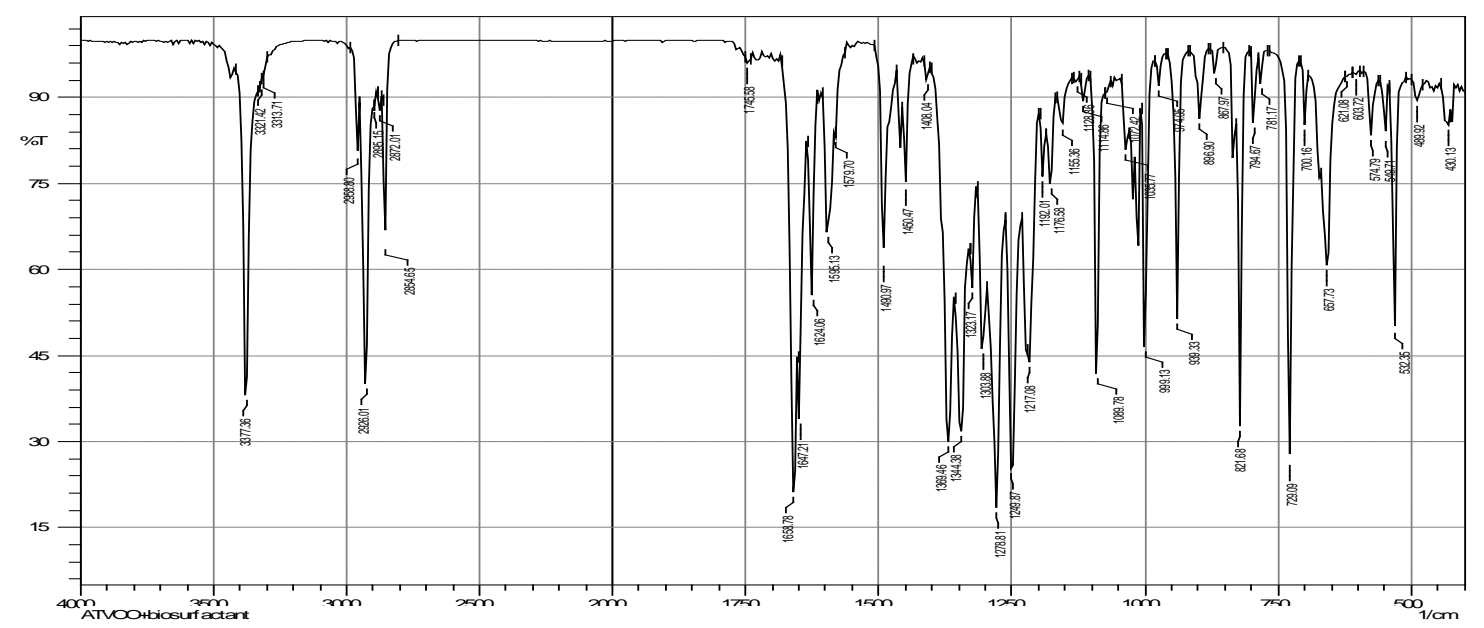

Fig. 1: FTIR of atovaquone and excipients

\section{Solid dispersion of atovaquone}

The dissolution medium in United State pharmacopeia (USP) for atovaquone drug is isopropyl alcohol $40 \% \mathrm{v} / \mathrm{v}$ with potassium hydrogen phosphate $\mathrm{pH}$ 8. In the present study $0.1 \mathrm{~N}$ hydrochloric acid $\mathrm{pH} 1.2$ dissolution medium was used to mimic the biological fluid. All the formulated solid dispersion batches, dissolution rate profiles were shown in the fig. 2. Batch S1 showed two fold increases in dissolution rate in accordance with batch S0. All the formulation batches of ternary systems of biosurfactant showed an average twofold increase in the dissolution rate as compared to all batches of poloaxmer 407. Enhanced percentage of dissolution rate of atovaquone drug could be the effective penetration and wettability by biosurfactant, a similar study was reported by Swati S et al. [16]. Dissolution rates of batch S3 and S4 did not show significant differences in the percentage of drug release. Hence S3 formulation was chosen for further study. A comparative dissolution profile of binary and ternary systems of solid dispersion is shown in fig. 3 .

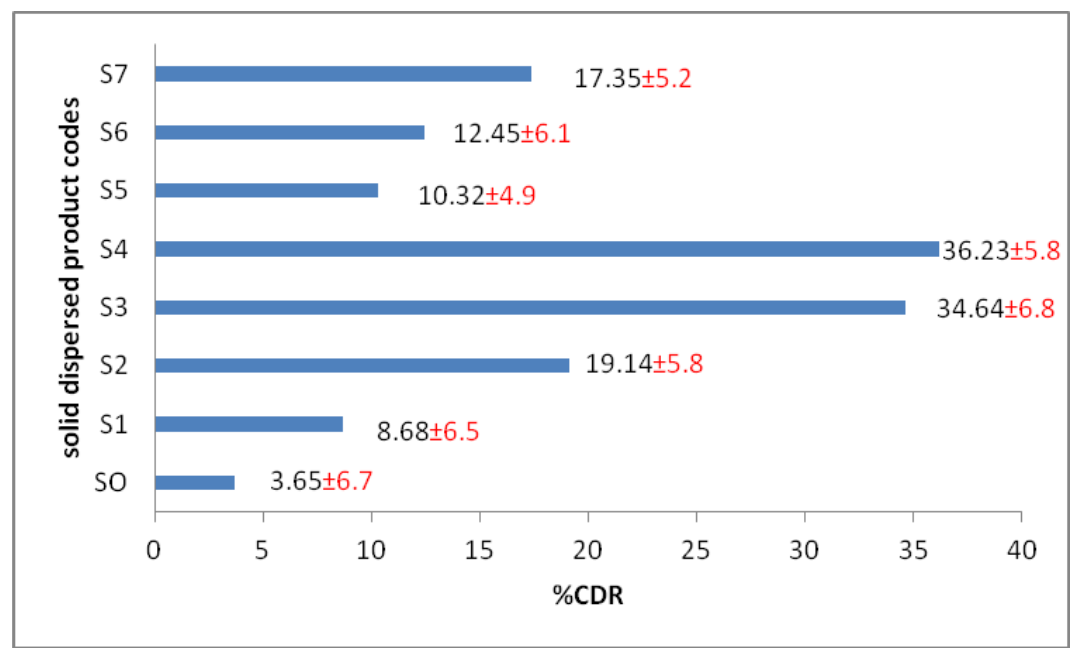

Fig. 2: Comparative dissolution profile of solid dispersed products from $S 0$ to $S 7$ for $1 \mathrm{~h} .(\mathrm{n}=3)(\mathrm{mean} \pm \mathrm{SD})$ 


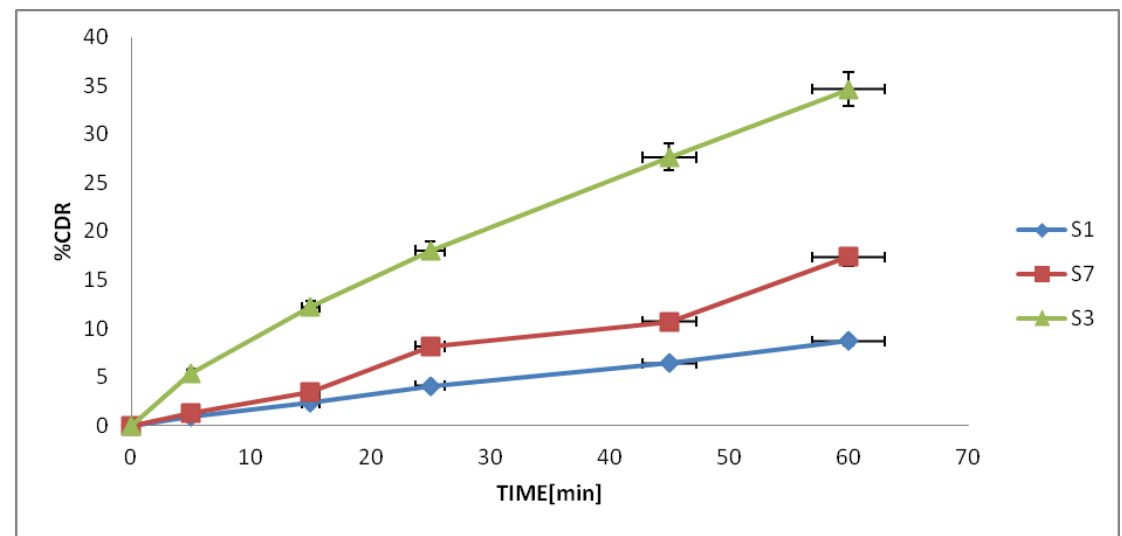

Fig. 3: Comparative dissolution profile of binary (S1) and ternary system of solid dispersion (S3, S7). (n=3) (mean \pm SD)

\section{Atovaquone tablet evaluation}

Atovaquone tablets formulations were prepared from the physical mixture (F1, F2, F3) and solid dispersed product blends of binary (F4) and ternary systems (F5, F6) using the dry granulation method. These two processing steps (physical mixture and solid dispersion) were adapted to atovaquone tablet preparation, to evaluate the appropriate method of addition of surfactants to achieve an enhanced dissolution rate of atovaquone.

\section{Pre-compression}

All the formulated atovaquone formulation powder blends were subjected for micromeritics properties. The compressibility index, Hausner's ratio, and angle of repose were within the specified limits of $10.8 \%$ to $12.19 \%, 1.11$ to 1.27 and 25.60 to 28.30 respectively. From table 3 results indicates that all formulations were having a good free flowing and compressible properties.

Table 3: Micrometric properties of lubricated powder of atovaquone

\begin{tabular}{|c|c|c|c|c|c|}
\hline $\begin{array}{l}\text { Formulation } \\
\text { code }\end{array}$ & $\begin{array}{l}\text { Bulk density* } \\
\left(\mathrm{g} / \mathrm{cm}^{3}\right)\end{array}$ & $\begin{array}{l}\text { Tapped density* } \\
\left(\mathrm{g} / \mathrm{cm}^{3}\right)\end{array}$ & Compressibility index $(\%)^{*}$ & Hausner's ratio* & Angle of repose* \\
\hline F1 & $0.49 \pm 0.02$ & $0.55 \pm 0.02$ & $12.19 \pm 0.03$ & $1.13 \pm 0.08$ & $25.60 \pm 2.07$ \\
\hline $\mathrm{F} 2$ & $0.48 \pm 0.01$ & $0.54 \pm 0.04$ & $10.83 \pm 0.04$ & $1.11 \pm 0.07$ & $26.71 \pm 0.57$ \\
\hline F3 & $0.47 \pm 0.09$ & $0.55 \pm 0.03$ & $10.89 \pm 0.04$ & $1.12 \pm 0.04$ & $27.13 \pm 0.75$ \\
\hline $\mathrm{F} 4$ & $0.48 \pm 0.08$ & $0.53 \pm 0.02$ & $13.01 \pm 0.01$ & $1.13 \pm 0.04$ & $26.40 \pm 0.43$ \\
\hline F5 & $0.47 \pm 0.01$ & $0.53 \pm 0.02$ & $11.70 \pm 0.07$ & $1.10 \pm 0.02$ & $27.58 \pm 0.35$ \\
\hline F6 & $0.48 \pm 0.03$ & $0.53 \pm 0.04$ & $10.93 \pm 0.09$ & $1.13 \pm 0.09$ & $28.30 \pm 0.01$ \\
\hline
\end{tabular}

*mean \pm SD $(n=6)$

Table 4: Post-compression parameters

\begin{tabular}{llllcc}
\hline Code & Weight variation * $\mathbf{( m g )}$ & $\begin{array}{l}\text { Thickness } \\
(\mathbf{m m})\end{array}$ & $\begin{array}{l}\text { Hardness } \\
\left(\mathbf{k g} / \mathbf{c m}^{2}\right)^{*}\end{array}$ & Friability (\%)* & $\begin{array}{l}\text { Drug Content } \\
(\mathbf{\%})^{*}\end{array}$ \\
\hline F1 & $230 \pm 2.01$ & $3.5 \pm 0.5$ & $3.3 \pm 0.35$ & $0.32 \pm 0.091$ & $98.22 \pm 0.50$ \\
F2 & $230 \pm 3.04$ & $3.5 \pm 0.6$ & $3.5 \pm 0.50$ & $0.39 \pm 0.015$ & $96.70 \pm 1.06$ \\
F3 & $230 \pm 3.25$ & $3.5 \pm 0.5$ & $3.3 \pm 0.35$ & $0.36 \pm 0.028$ & $99.05 \pm 0.43$ \\
F4 & $230 \pm 2.02$ & $4.5 \pm 0.5$ & $3.4 \pm 0.40$ & $0.19 \pm 0.041$ & $98.03 \pm 0.37$ \\
F5 & $230 \pm 3.05$ & $4.25 \pm 0.5$ & $3.3 \pm 0.35$ & $0.21 \pm 0.028$ & $97.45 \pm 0.43$ \\
F6 & $230 \pm 3.04$ & $3.35 \pm 0.5$ & $3.40 \pm 0.40$ & $0.25 \pm 0.013$ & $98.25 \pm 0.37$ \\
\hline
\end{tabular}

${ }^{*}$ mean \pm SD $(n=6)$

\section{Post-compression}

Pharmacopieal and non-pharmacopieal tests for atovaquone tablets results were shown in the table 4 . Weight variation test, thickness, hardness, friability, and drug content results were within the specified limits. Results of disintegration test for batch F2 and F5 indicated that addition of biosurfactant in the ternary system can improve the disintegration time. Similar results were also reported by Shaji A et al. [17].

\section{In vitro dissolution profile}

In vitro dissolution of a physical blend of atovaquone tablets F1, F2 and $\mathrm{F} 3$ showed $5.7 \%, 9.0 \%$ and $7.23 \%$ drug release respectively.
Binary and ternary blend system atovaquone tablets, F4, F5 and F6 showed $10.95 \%, 37.65 \%$ and $18.64 \%$ respectively (fig. 4). The numbers of fold increase in dissolution efficiency for F2, F3, F4, F5, and F6 were $1.44,1.28,1.94,6.62$, and 3.51 respectively (table 5). In vitro dissolution profile revealed that physical mixture blend(F2) and the ternary system blend (F5) of biosurfactant showed 2 fold and 6.6 fold an increase in the percentage of dissolution rate respectively, calculated at DE45. From these results conclude that the most effective step for the addition of surfactant in the tablet formulation was in the ternary system. Mohamed FK et al. [18] reported that addition of surfactant in ternary solid dispersion system showed an increased in dissolution rate of less water-soluble drug. 


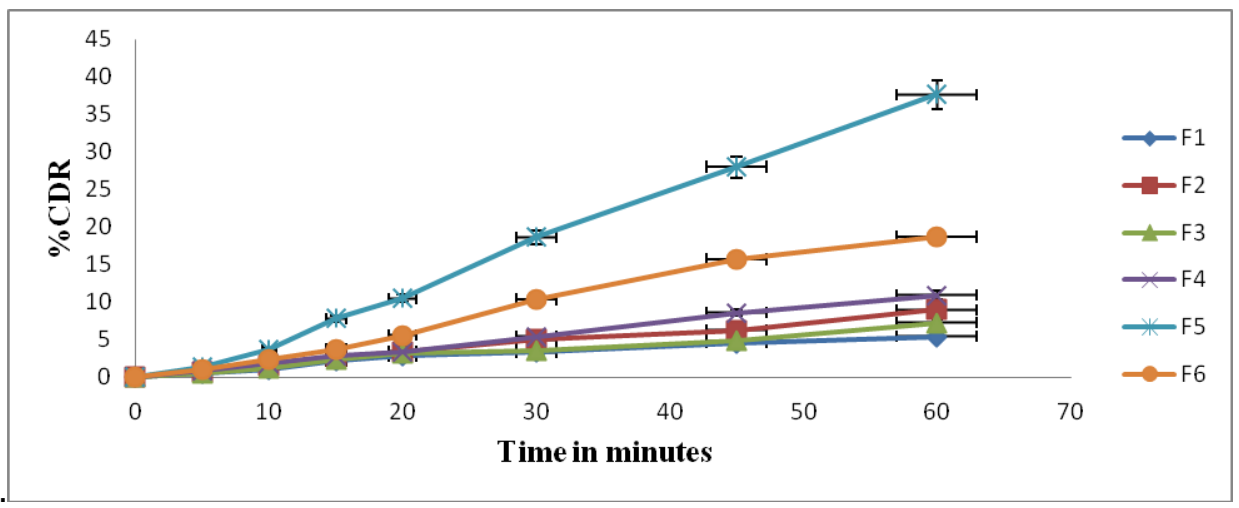

Fig. 4: In vitro dissolution of atovaquone tablet F1 to F6. $(\mathrm{n}=3)(\mathrm{mean} \pm \mathrm{SD})$

Table 5: Dissolution efficiency of F1 to F6 $(n=3)($ mean \pm SD)

\begin{tabular}{llllll}
\hline Formulation & F1 & F2 & F3 & F4 & F5 \\
\hline DE45 & $5.02 \pm 5.3$ & $7.2 \pm 6.8$ & $6.45 \pm 7.2$ & $9.75 \pm 5.8$ & $33.25 \pm 4.8$ \\
No of fold increase in dissolution rate & --- & 1.44 & 1.28 & 1.94 & 6.62 \\
\hline
\end{tabular}

\section{In vivo study}

From in vivo data, model-independent pharmacokinetic parameters, Cmax, tmax, and AUC were summarized in the table 6. The mean AUC of F5 and oral suspension were $240.73 \mu \mathrm{g} / \mathrm{ml} / \mathrm{h}$ and $88.71 \mu \mathrm{g} / \mathrm{ml} / \mathrm{h}$ respectively. Formulation F5 exhibited a significant increase Cmax: 3 folds and tmax was shortened by $1.4 \mathrm{~h}$ in accordance to oral suspension (fig. 5). Formulation strategy for BCS class IV drug has been met with moderate success by incorporation of biosurfactant in the atovaquone dosage form. The beneficial effect of biosurfactant could be enhanced solubility-dissolution kinetics is the probable driving force behind the improved pharmacokinetic properties and effective softening of tight junction of the intestinal cell lining. Improved bioavailability study was reported by Borhardev et al. [19].

Table 6: In vivo study of F5 and oral suspension

\begin{tabular}{lll}
\hline PK parameters & Oral suspension* & \multicolumn{1}{c}{ F5 $^{*}$} \\
\hline $\mathrm{Cmax} \mu \mathrm{g} / \mathrm{ml}$ & $10.56 \pm 12.51$ & $30.12 \pm 14.32$ \\
$\mathrm{t} \max \mathrm{h}$ & $6.5 \pm 14.32$ & $5.1 \pm 13.58$ \\
$\mathrm{AUC} \mu \mathrm{g} / \mathrm{ml} / \mathrm{h}$ & $88.71 \pm 23.17$ & $240.73 \pm 24.56$ \\
\hline
\end{tabular}

${ }^{*}$ mean \pm SD $(\mathrm{n}=3)$

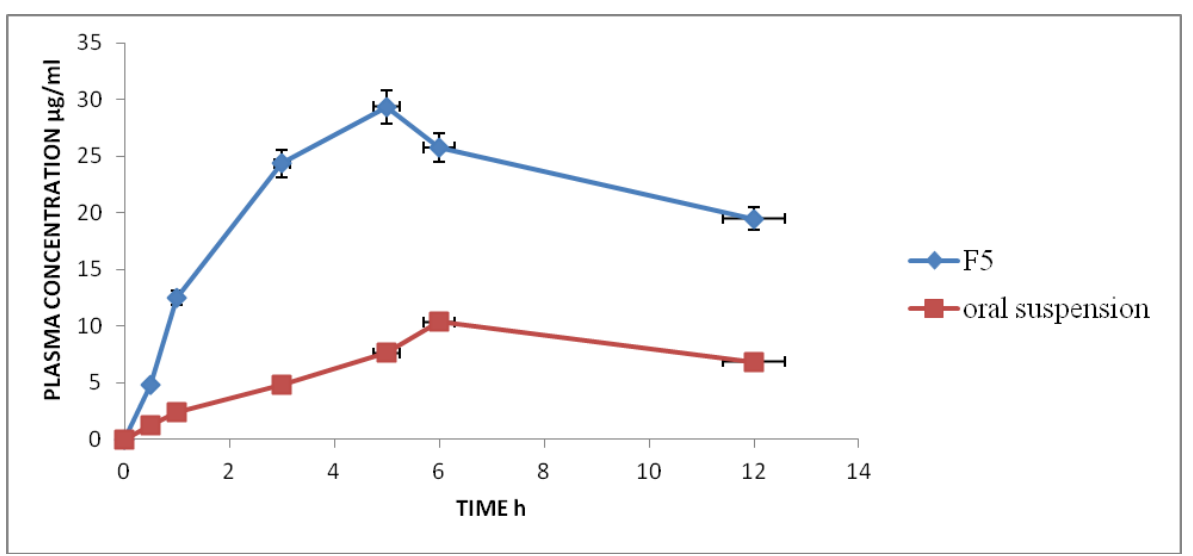

Fig. 5: In vivo study of F5 and atovaquone suspension. ( $\mathrm{n}=3$ ) (mean $\pm \mathrm{SD})$

\section{CONCLUSION}

The main objective of the present study was to evaluate the effect of biosurfactant on dissolution rate and bioavailability of BCS class IV drug. Atovaquone was selected as a model drug. Formulations of a solid dispersion in a binary and ternary system with biosurfactant and synthetic surfactants were prepared and compared. The ternary system was proved to be better than the binary system for enhancement of dissolution rate. Atovaquone tablets prepared from physical mixture blend and solid dispersed products. Evaluated results indicated that addition of biosurfactant in the ternary system better than the physical mixture. In vivo study indicated the biosurfactant can also act as bioenhancer for BCS class IV drugs. However, detailed toxicology and stability studies are needed for the biosurfactant to be approved from regulatory authorities as the surface active agent.

\section{ACKNOWLEDGMENT}

Authors are thankful to the principal of KLE College of pharmacy Belagavi for providing all facilities for the conduct of research 
project. We also thankful to Matrix Lab Ltd Hyderabad for gift sample of atovaquone.

Financial support and sponsorship: Nil.

\section{AUTHORS CONTRIBUTIONS}

All the authors have contributed equally

\section{CONFLICT OF INTERESTS}

The authors declare that there is no conflict of interest

\section{REFERENCES}

1. Araon LB, David RH. Antiparasitic agent atovaquone. Antimicrob Agents Chemother 2002;46:1163-73.

2. Sek L, Boyd BJ. Examination of the impact of a range of pluronic surfactants on the in vitro solubilization behavior and oral bioavailability of lipidic formulations of atovaquone. J Pharm Pharmacol 2006;58:809-20.

3. Venkatram, Roger JA. Characteristics of drug-phospholipid coprecipitates I: physical properties and dissolution behavior of griseofulvin-dimyristoyl phosphatidylcholine systems. J Pharm Sci 1984;73:757-61.

4. Vishal J, Parekh, Patravale VB, Aniruddha B, Pandit. Mango kernel fat: a novel lipid source for the fermentative production of sophorolipid biosurfactant using starmerella bombicola NRRL-Y 17069. Ann Biol Res 2012;3:1798-803.

5. Karadi RV, Lokesh KN, Channarayappa MV, Venkataranganna, Bindu S, Sivakiran RR. Standardization of biosurfactant enrichment process by factorial design and elucidating its physicochemical and structural characteristics. J Biochem Tech 2012;3:161-6.

6. Zoeller T, Dressman JB, Klein S. Application of a ternary HP- $\beta$ CD-complex approach to improving the dissolution performance of a poorly soluble weak acid under relevant conditions. Int J Pharm 2012;430:176-83.

7. Patil AN, Shinkar DM, Saudagar RB. Review article: solubility enhancement by solid dispersion. Int J Curr Pharm Res 2017;9:15-8.
8. Biswas M, Akogyeram CO, Scott KR, Potti GK, Gallelli JF, Habib MJ. Development of carbamazepine: phospholipid solid dispersion formulations. J Controlled Release 1993;23:239-45.

9. Eraga SO, Arhewoh MI, Okunzuwa JI, Iwuagwu MA. Preliminary investigation of the mucoadhesive properties of thermally modified mucin on metronidazole tablets. Int J Pharm Pharm Sci 2015; 7:96-00.

10. Kishore BA, Ramana MV. Development and in vivo evaluation of gastroretentive floating tablets of antipsychotic drug risperidone. Int J Pharm Pharm Sci 2016;8:43-52.

11. Wadher KJ, Kakde RB, Umekar MJ. Formulation and evaluation of sustained-release tablets of metformin hydrochloride using hydrophilic synthetic and hydrophobic natural polymers. Indian J Pharm Sci 2011;73:208-15.

12. Khan KA, Rhodes CT. The concept of dissolution efficiency. J Pharm Pharmacol 1975;27:48-9.

13. Koh PT, Chuah JN, Talekar M, Gorajana A, Garg S. Formulation development and dissolution rate enhancement of efavirenz by solid dispersion systems. Indian J Pharm Sci 2013;75:291-301.

14. DeAngelis DV, Long JD, Kanics LL, Woolley JL. High-performance liquid chromatographic assay for the measurement of atovaquone in plasma. J Chromatogr 1994;652:211-9.

15. Reddy SD, Rao PB. Development and in vitro-in vivo evaluation of controlled release matrix tablets of desvenlafaxine. Pharmacol Pharm 2012;3:15-9.

16. Sareen S, George M, Josep L. Improvement insolubility of poorly water-soluble by solid dispersion. Int J Pharm Investig 201;2:12-7.

17. Shaiji J, Bhatia V. Dissolution enhancement of atovaquone through cyclodextrin complexation and phospholipid solid dispersion. Int J Pharm Pharm Sci 2013;5:642-50.

18. Mohammad FK, Muhammad SBS, Khan RI, Tahiatul SM, Saiful I. Study of the binary and ternary solid dispersion of ibuprofen for the enhancement of oral bioavailability. Appi Pharm Sci 2011;1:103-7.

19. Borhardev, Patak S, Sharma S, Patravale V. Formulation and characterization of atovaquone nanosuspension for improved oral delivery in the treatment of malaria. Nanomedicine 2014;5:649-66. 